\title{
Coherentism and Justified Inconsistent Beliefs: A Solution
}

\author{
Jonathan L. Kvanvig
}

\section{Introduction}

Problems for coherentism come in two forms. The fundamental issue that coherentists have not been very successful in addressing is the problem of saying precisely what coherence involves. BonJour's account in The Structure of Empirical Knowledge is among the most detailed available, but he admits that it "is a long way from being as definitive as desirable." ${ }^{1}$ More recently, he has been more pointed, writing that "the precise nature of coherence remains an unsolved problem." 2

Recently, some hope has emerged that progress can be made on this issue, ${ }^{3}$ but the more pressing problem for coherentism comes in the form of objections to the view that are independent of any particular construal of the coherence relation itself. These problems are more pressing, since if these objections are correct, coherentists need not waste their time explicating the nature of coherence-the view would be false independently of these details. Among these objections are the claims that coherentism cannot account for the essential role of experience in justification (commonly termed the isolation objection), that coherentism cannot correctly explain what it is to base one's beliefs properly, and that coherentism cannot explain properly the relationship between justification and truth (one version of which is often called the alternative systems objection). My view of the matter is that none of these objections decisively undermine coherentism, ${ }^{4}$ but there is one version of the problem of the relationship between justification and truth that is, to my mind, the most pressing difficulty coherentism faces. It is the problem

\footnotetext{
${ }^{1}$ BonJour 1985, p. 101.

${ }^{2}$ BonJour 1999, p. 124.

${ }^{3}$ See, e.g., (Bovens and Hartmann 2003b,a).

${ }^{4}$ As argued in (Kvanvig 1995a,b, 2003, Kvanvig and Riggs 1992).
} 
of justified inconsistent beliefs. In a nutshell, there are cases in which our beliefs appear to be both fully rational and justified, and yet the contents of the beliefs are inconsistent, often knowingly so. This fact contradicts the seemingly obvious idea that a minimal requirement for coherence is logical consistency.

Here I present a solution to one version of this problem. I will first explain this problem of justified inconsistent beliefs for coherentism, and then show how to avoid it. To anticipate my argument, the key is to note that there are distinct types of justification. There is the ordinary intuitive notion on which justification obtains when one believes in accord with what the evidence favors. Coherentists, however, are interested in the type of justification that is part of a proper account of knowledge, the kind of justification which is such that if it is unGettiered and conjoined to true belief, yields knowledge. In slogan form, I will summarize this idea as by saying that the kind of justification in question for coherentists is the kind that puts one in a position to know. The distinction between the two types of justification arises because one's evidence might favor a particular point of view, but not favor it strongly enough to put one in a position to know. Any examples of the distinction are likely to be controversial, but perhaps our cherished philosophical viewpoints are as good an example as any. We believe what we do philosophically because we think that the evidence favors this viewpoint. But for many of us, at least, we don't take our positive views in philosophy to count as knowledge, and we think they don't count as knowledge because we think the evidence in favor of our views isn't compelling enough to put us in a position to know. I will call the kind of justification that puts one in a position to know "epistemic justification", and when I intend to talk about the more ordinary, commonplace justification that need not put one in a position to know, I will use the term 'justification' without the qualifier or the phrase 'ordinary justification'. I will argue, in my preferred terminology, that epistemic justification cannot be identified with justification. The key to solving the problem of justified inconsistent beliefs, then, is to allow that they are possible on the ordinary intuitive notion of justification but not on the kind of justification that puts one in a position to know. The trick is to substantiate these claims and not rely simply on the claim that such a distinction can be drawn. I will do so with little more in the way of assumptions than a relatively well-understood form of internalism, something coherentists (and others) typically embrace.

In order to prevent misunderstanding, let me state more carefully what I 
will not argue for. I am not going to argue that coherentism is true, or even that there are good reasons to believe it. Nor am I going to argue that the special brand of internalism I will employ is the correct form and that other forms are inadequate. In this way, my defense of coherentism may raise other problems for the view. That's an acceptable cost if incurred, since if I'm right we will have made intellectual progress at least in finding out what direction a defense of coherentism must go. In this sense, I am going to eliminate one affliction for coherentism, leaving open that there may be other afflictions and leaving open as well that eliminating one blight may call attention to others.

\section{The Problem of Justified Inconsistent Be- liefs}

First, let us be clear about the problem of justified inconsistent beliefs. The best account of the version I will address here is Richard Foley's, ${ }^{5}$ appealing to lottery and preface paradoxes as examples. In the lottery case, for example, one can have a justified belief that one's ticket will lose, since the probability of losing can be arbitrarily high, depending on how one envisions the particular lottery. The same reasons for thinking that one's own ticket will lose are reasons for thinking that any particular ticket will lose, and thus one is justified in believing of each ticket that it will lose. This set of beliefs is inconsistent with one's knowledge that there will be a winner of the lottery, and thus it is possible for there to be justified inconsistent beliefs.

A similar argument appeals to the preface paradox. One can write a book and be as justified as one cares to imagine (short of infallible certainty) in believing each of the claims of the book. Since the book is complicated and long, however, one is also justified in believing the preface claim that in spite of one's best efforts, errors remain. This set of justified beliefs is inconsistent.

The preface paradox is an analogue of the predicament fallible cognizers face. If we do our best, our ordinary beliefs might all be justified. But since we know that we are fallible, we are also justified in believing that some of our ordinary beliefs are false. The complete set of justified beliefs for reflective fallible cognizers is, therefore, inconsistent.

The possibility of justified inconsistent beliefs is a threat to coherentism

\footnotetext{
${ }^{5}$ Foley 1979.
} 
in the following way. As already noted, it is a notoriously difficult thing to say precisely what coherence involves, but it is a plausible starting point to assume that coherence requires, at a minimum, logical consistency. If so, however, no inconsistent set of beliefs could be justified, contrary to the lessons of the lottery and preface paradoxes, as well as facts concerning our own fallibility. Until the problem of justified inconsistent beliefs became known, such a minimal requirement was never questioned. Thus, the possibility of justified inconsistent beliefs poses a serious threat to the plausibility of coherentism.

There is another version of the problem of justified inconsistent beliefs. The second problem is the problem of necessary falsehoods and the possibility of being justified in believing them. Regarding this version of the problem, we should distinguish between necessarily false beliefs that are inconsistent from those that are necessarily false but not inconsistent, since no reasonable constraint on coherence could require that consistent but necessarily false claims are incapable of cohering with an appropriate system. An inconsistent belief is one from which the falsum constant $\perp$ can be derived in the preferred logic (so that, in that logic, $\ulcorner\alpha \rightarrow \perp\urcorner$ is logically equivalent to $\ulcorner\sim \alpha\urcorner$ ). A necessarily false proposition need not be inconsistent, but may be. So the problem of justified inconsistent beliefs is only a problem for those beliefs from which this falsum constant can be derived.

My goal here is primarily to address the former problem rather than this latter one, but I will begin with a few remarks about why the former problem is more severe than the latter. In a word, the latter problem is an artifact of a philosophical theory about mental content that has no hope of solving the Fregean problem of cognitive significance. If we think of beliefs in terms of an attitude operator governing a proposition, and adopt a standard theory of propositions on which it is quite easy for the same operator-proposition combination to fall short of explaining the cognitive significance of such doxastic commitment, it is no surprise that, on such a theory, inconsistency unawares can plague one's epistemology. For example, if our theory treats belief that Cicero is Roman as identical to the belief that Tully was Roman, it should surprise no one that rational inconsistencies can arise. The problem, however, is not best thought of as a problem to be solved by a better epistemology, but rather a problem to be solved by a better philosophy of mind. Recent work on two-dimensional semantics offers some hope of accounting for the 
obvious difference between believing under different modes of presentation, ${ }^{6}$ to use Fregean language, and coherentists can take some comfort in such developments. For, once a suitably fine-grained approach to mental content is in place, there is reason to think that something within the content itself will be useable to explain how the content as a whole can cohere with a belief system in spite of the fact that some aspect of that content is unknowingly inconsistent. It is essential to the phenomenon of single-proposition inconsistent belief that there be something in the total story of mental content to address the cognitive significance of the belief that involves a kind of semantic blindness to the inconsistency. This fact allows the coherentist to pass off the difficulty as one within the philosophy of mind rather than some difficulty that undermines coherentism.

For example, if we identify the two different dimensions of meaning, one of which involves something like a function from worlds to truth values, and another of which involves some other notion more closely tied to epistemic possibility, $^{7}$ a coherentist can grant that the inconsistency involved in the former dimension of meaning might not be the appropriate dimension to focus on when doing epistemology. So long as the dimension associated with epistemic possibility involves semantic information that is itself consistent, coherentists need not fret that a philosophy of mind with a more Procrustean notion of content leaves no room for accommodating individual beliefs that cannot be true. It would still be within the spirit of an approach to justification that makes consistency a sine qua non of justification that consistency be available along some dimension of meaning even if not available in terms of the propositional content itself.

Of course, none of this is far from definitive, but is intended only to be suggestive of a possibility open to coherentists for single-belief inconsistencies and which is not open to coherentists for the inconsistencies involved in the paradoxes. For, in those cases, the inconsistency is a known inconsistency, knowledge of which is compatible with the beliefs being justified nonetheless. Hence there is no dimension of meaning closely tied to or associated with epistemic possibility that could be used to blunt the force of the argument against coherentism deriving from justified by knowingly inconsistent sets of beliefs. For this reason, the threat to coherentism from justified inconsistent sets of belief, such as are arguably present in the paradoxes mentioned above,

\footnotetext{
${ }^{6}$ See, e.g., (Garcia-Carpintero and Macià 2005).

${ }^{7}$ For further discussion, see especially (Chalmers 2004).
} 
is a more serious challenge that the single-belief problem.

Our focus will thus be on the problem of sets of beliefs, each member of which is consistent, but where the set itself is not consistent. There are a couple of approaches to this problem that may provide hope for coherentists. One is found in the work of an anti-coherentist, John Pollock. Pollock holds that lottery and preface need to be treated differently, with lottery solved by noting that each claim regarding the losing status of a particular ticket is negatively relevant to every other such claim, resulting in what he terms "collective defeat" of each particular claim that a given ticket will lose. The preface paradox is handled on his view differently. Pollock holds that every claim in the book can be justified, as well as the claim that the book is of a type that generally contains errors. What is not allowed is inferring from this latter claim that this very book contains errors, or is highly likely to contain errors, since the argument here is defeated by the claim that all the claims in the book are true. ${ }^{8}$

If this approach is successful, it would be a happy result for coherentists. Pollock is attempting to characterize the ordinary notion of rationality, not some related concept suitable for inclusion in an account of the nature of knowledge. So if his attempt is successful, there would be no need to exploit some distinction between ordinary notions of rationality and justification and those playing a certain role in an account of knowledge.

I will not here rely on Pollock's strategy however, for two reasons. The first is straightforward and compelling, and the second is more suggestive and, we might say, continental in perspective. The first is that Pollock's goal is to give an account of rational belief, a project that he explicitly characterizes as orthogonal to the project of constructing a theory of justified belief that is an appropriate element within a complete theory of knowledge. Coherentists, however, typically aim at providing an account of justification that can function as the third component in a theory of knowledge. If Pollock's account and the coherentist account are orthogonal to each other in this way, it would take more work to show that Pollock's solution can be extended to a solution to the problem of justified inconsistent beliefs in the theory of knowledge setting.

One might hold that rationality in the sense Pollock is investigating is at least a necessary condition for the kind of justification necessary for knowledge, and I am sympathetic to this idea. But the language of orthogonality

\footnotetext{
${ }^{8}$ Pollock 1986.
} 
wouldn't be appropriate if rationality were necessary for justification.

None of this implies that Pollock's approach wouldn't be fruitful for coherentists to exploit, but the work that would need to be done to connect the project of specifying the nature of rule-following rationality and the project of specifying the nature of justification when it is assumed to be necessary for knowledge is not simple or trivial work. I would welcome such an account, but I don't have one, so I'll give what I've got instead.

The other reason for not relying on Pollock's account is that I am concerned about one aspect of it's resolution of the preface paradox. One specific example of the preface paradox is the paradox of fallibility, where the preface statement is the fallibilist's motto that some of my (other) present beliefs are false and the contents of the book are all these other beliefs. Given the above account of the Preface Paradox, Pollock's strategy tells me I can't have this metabelief, but only some weaker claim. My worry is whether one can adequately account for the nature of fallibility and our awareness of it with a weaker claim.

One might wonder whether there is an issue here at all. Why not simply note that our awareness of our own fallibility resides in the straightforward and simple belief that we are fallible. What could be more obvious?

Things are not that simple, however. The term 'fallible' is a modal one, and so the simple belief that I am fallible involves a possibility claim of some sort. Perhaps the idea is that it is possible that I am in error about some of my beliefs. I believe that claim is true, but upon hearing it I would think the proper attitude is that it is much too weak an expression of humility. After all, it is perfectly consistent to note a possibility while pointing out that it is unrealized. We do that when explaining what contingent truths are to students: they are truths which might have been false. But it is no proper expression of epistemic humility to point out that even though it is possible that I hold a false belief, I really don't.

Perhaps there is a modality that prohibits such concessions, so that it is contradictory to say, in that modality, "I might be wrong but I'm not." 9 If there were such a modality, one might then insist that epistemic humility is best expressed using that modality, since it couldn't be conjoined to a denial of being wrong.

It is implausible, however, to think that there is such a modality. Such

\footnotetext{
${ }^{9}$ For a defense of this claim, see (Lewis 1996). For discussion of needed qualifications, see (Stanley 2005, Dougherty and Rysiew 2009).
} 
remarks might be generally or almost always or even flat-out always infelicitous, but to claim that the explanation of the infelicity must always and everywhere be semantic is more than can be defended. Hence, there simply isn't a modal notion of the required sort to be exploited to express epistemic humility in way robust enough to count as a proper expression of our actual condition.

So something more than the straightfoward and simple approach is needed here. We might try to cash out the talk of possibility in terms of probability instead, in something like the following. Perhaps I am entitled to the more general claim that all my past selves have had false beliefs. I can't have the metabelief that some of present beliefs are false if I'm justified in believing all my other beliefs, since they would then provide a defeater of the inference from this claim about my past fallible selves to my present fallible self.

I'm not comfortable with this account. There is a pessimistic metainduction about the plausibility of current scientific theories, based on the failure of all past theories. I don't think my sense of my own fallibility is like that. I don't think the pessimistic metainduction succeeds at undermining the plausibility of current scientific theories, but I also don't think that my sense of my own fallibility is analogous to this case. When describing my fallibility, I don't just point to the false beliefs of my past selves, though that may be part of what I do. My sense of my own fallibility, and here I think my experience is nearly universal, is different from my sense of the failures of my past selves to land the truth.

So perhaps we should look in a different direction. Instead of deriving our sense of fallibility from our past selves, perhaps it derives from our sense that it is a common human characteristic to have false beliefs. We still wouldn't be able to use this beliefs to reason to the conclusion that some of one's own beliefs are false, since that inference is defeated by the justificatory status of the rest of one's beliefs. Because the inference is blocked, this account underrepresents our sense of fallibility. It puts me, for example, in exactly the same situation as a completely arrogant person whose behavior displays a presupposition that he or she is immune from this common human foible. Of course, if such arrogance is represented in the form of belief, then we have a cognitive basis to distinguish them from us. But if they have no such belief, and my own sense of fallibility is only rationally allowed expression in the form of a general belief about the intellectual foibles of humanity, then such a person has precisely the same cognitive grip on his or her own fallibility as I do. I think they don't, however, and I think that any adequate account of 
an appropriate sense of our own fallibility is going to require more in the way of doxastic commitment than just that our past selves and human beings in general usually have false beliefs.

These last two attempts are specific instances of the general strategy of trying to express our sense of fallibility in terms of believing some particular incarnation of a claim that strongly supports that it is quite likely that some of my present beliefs are false. So perhaps it would be best just to employ this claim directly, rather than adopt some more particular claim that counts strongly in its favor.

We should be skeptical here, however, for a reason similar to the one above. This claim is at least not a suitable complete expression of fallibility, since I can add to it the claim that none of my beliefs are actually false in spite of the likelihood in question. So, at the least, we'd have to stipulate that the general likelihood belief is not accompanied by outlandish tendencies toward arrogance. Yet, it is surely not an adequate account of my own sense of fallibility to point to a belief of mine that expresses this sense, but only when unaccompanied by tendencies to arrogance. What we want is an account of my sense of fallibility that, by itself, expresses that sense.

The kind of account I want is one in which this sense is expressed cognitively in the form of doxastic states or degrees of such for fans of finer-grained epistemology. So what I want is a belief or collection of beliefs that encode my sense of fallibility. I won't be satisfied with an account that gives me a belief and tells me that it expresses my sense of fallibility so long as there aren't any other beliefs in my head that prevent this belief from being my fallibilist belief. So I think the mere likelihood belief isn't sufficient for explaining what I want explained.

I should note that I'm assuming here that our sense of fallibility has a cognitive expression rather than being merely attitudinal, and one might wonder whether this assumption is warranted. It is important to note that our sense of fallibility fits naturally with attitudes such as open-mindedness and a non-dogmatic approach to inquiry, whether individual or corporate. But it would immensely surprising if our sense of fallibility itself were not encoded cognitively, since we should expect the explanation of the appropriate attitudes in question to be explained not only by the fact that we are fallible but also by our awareness, our sense, of this important fact about us. So the assumption that our sense of fallibility has cognitive expression is just the right assumption.

In slogan form, then, I am concerned that Pollock's conclusions don't 
allow a proper place for epistemic humility. I am not claiming, however, that Pollock's approach is mistaken because of this concern. His recent work extends his earlier work on defeaters to the more general topic of diminishers, where a diminisher decreases but does not eliminate the justification an argument provides for a given claim. ${ }^{10}$ It may be that an approach involving diminution of justification will still allow enough justification to allow sufficient expression of intellectual humility, though it is not clear to me that it has this capacity. In light of my uncertainty, I want to pursue a different approach for dealing with the problem of justified inconsistent beliefs. If Pollock's approach is able to account properly for epistemic humility, the coherentist will then have two independent responses to give, and that situation would present no cause for consternation by coherentists.

A different reaction to the problem is adopted by William Lycan, himself a self-described coherentist. He has maintained that logical consistency is not a requirement for justification, but only a justification-enhancer. ${ }^{11} \mathrm{He}$ has proposed that consistency only be required in subparts of the total belief system, with failure of global consistency decreasing overall coherence but not eliminating it entirely. ${ }^{12}$

For several reasons, I think we should not be satisifed with this response to the problem of justified inconsistent beliefs. First, it has no motivation apart from the need to escape the problem for coherentism posed by the possibility of justified inconsistent beliefs. Had the problem of justified inconsistent beliefs never emerged, it is hard to see why anyone would have suggested or contemplated the idea that coherence might not require consistency. Second, Lycan gives us no help with the issue of how to carve a belief system into subparts in which coherence is required. In the cases of the preface paradox and the fallibility condition, the natural procedure would be to separate first-order beliefs and meta-beliefs into separate compartments, but such a carving procedure will not help in the case of the lottery paradox. In the case of the lottery paradox, one will have to put particular beliefs, such as the belief that a given ticket will lose, into a compartment different from that of the general belief that some ticket will win. If this general belief (together with some general claim about how many tickets there are) is in the same compartment as all the particular beliefs, the compartment itself

\footnotetext{
${ }^{10}$ See (Pollock 2001).

${ }^{11}$ Lycan 1996.

${ }^{12}$ Employing an idea that originated with Wayne Riggs, as Lycan notes.
} 
is inconsistent. In general, however, we do not want general and particular beliefs to be in different compartments. For example, if you believe that a particular example of lying is acceptable, but also think that all lying is unacceptable, we shouldn't put the two beliefs into different compartments and insist only that you achieve consistency within these compartments. Instead, we should insist that the inconsistency be avoided entirely if either of the beliefs in question is going to be justified.

One could respond on Lycan's behalf by adding to his approach the claim that sometimes inconsistency between compartments not only reduces overall justification for the conflicting beliefs, but eliminates it entirely. In this way, inconsistency between compartments could sometimes have the same effect as inconsistency with a compartment.

A willingness to posit enough epicycles is almost always a strategy good enough to save a theory from outright refutation. Yet, even if sufficient complexity can be developed to achieve just the right results, the ad hoc character of the overall proposal is still troubling. As far as I can tell, there is no motivation for Lycan's approach apart from the problem of justified inconsistent beliefs, nor is there any motivation for the latest complexity noted in the last paragraph apart from the inadequacy of the approach without it. I therefore suggest that coherentists should prefer to find a different solution to the problem of justified inconsistent beliefs.

\section{A New Solution}

My solution is this: the kind of justification that puts one in a position to know is different from the commonplace notion of justification or rationality employed in our intuitive judgements that, e.g., our own particular ticket in the lottery is a losing ticket. In one way, this proposal is not surprising: no one should be terribly surprised to find out that epistemic justification might be stronger than what is revealed by a careful investigation of the ordinary notion of justification or rationality. The burden comes in clarifying the difference and explaining how this difference enables the coherentist to escape the problem of justified inconsistent beliefs.

My claim in rough form, to be refined later, is this. If you justifiably believe that $p$ where the kind of justification in question is epistemic justification, then you have justification for believing that you know that $p$. If you

justifiably belief that $p$, but lack justification for believing that you know, 
then you have ordinary justification only.

In arguing for this idea, I will assume that a complete theory of knowledge will involve some version of the defeasibility theory: that knowledge can be identified with a kind of undefeated justified true belief. In addition to assuming the defeasibility theory, I will also assume a version of evidentialism, according to which what you are justified in believing is a matter of what your total evidence supports. Finally, I will regiment terminology in the following way. In my terminology, to justifiably believe something implies that one believes it, whereas to be justified in believing something requires that one has justification for the claim in question but leaves open whether or not it is believed by the individual in question. When one justifiably believes a given claim, doxastic justification is present; when a person is justified in believing a claim but does not in believe it, propositional justification is present but doxastic justification is not. A further possibility is the presence of both propositional justification and belief even though doxastic justification is absent. In such a case, one fails to base one's belief properly on that which propositionally justifies it.

The rough version of the claim I will argue for is, again, the claim that if you epistemically justifiably believe that $p$, you have justification for believing that you know that $p$. We assume, then, that you justifiably believe $p$. To defend the claim made about epistemic justification, I will argue that such epistemic justification involves justification for thinking that the conditions for knowledge obtain. I will quickly pass over the first two conditions for knowledge in order to focus on third condition, the justification condition, and the fourth condition, the Gettier condition. We can move past the truth condition quickly because it is fairly trivial to show that it is satisfied. To deny that one has adequate justification for the claim that $p$ is true when one justifiably believes $p$, one would have to hold that a body of evidence could confirm $p$ but not confirm that $p$ is true. While it is true that the argument that your evidence confirms that $p$ is true when it confirms $p$ relies on a closure principle of some sort regarding confirmation by evidence, there are no grounds for denying closure that extend to this case. So if you justifiably believe $p$, your total evidence confirms that $p$ is true.

The belief condition can be dispensed with quickly as well. On some views about our first-person epistemic authority, evidence that one believes $p$ when one does is an immediate consequence of our infallibility regarding what we believe. Others dissent, however. They hold that it is possible to justifiably believe that one doesn't believe $p$, even if in fact one does believe $p$. 
That is, one might object that justified false beliefs are possible about one's own mental states (and it would be a rather heterodox defense of coherentism to argue for it by requiring such infallibility). I agree that such justified false beliefs are possible (more circumspectly, I do not wish my argument to depend on this assumption). The conclusion that I want to demonstrate about epistemic justification - that it differs from ordinary justification in a way that allows the coherentist to escape the problem of justified inconsistent beliefs - doesn't need this assumption. Instead of defending that one always has good reasons for thinking that one believes a claim when one in fact does, I will qualify the thesis I wish to defend to avoid this issue altogether. Instead of saying that epistemic justification gives you justification for thinking that you know, we can say that epistemic justification gives you justification for thinking that the non-psychological, or epistemic, conditions for knowledge hold. ${ }^{13}$ Given the assumptions I am making here about the nature of knowledge, this amended principle claims that if you epistemically justifiably believe that $p$, then you have justification for believing that you have a justification that is not ultimately defeated by relevant information you do not possess. This new formulation is considerably more cumbersome than the earlier formulation, and in what follows I will generally use the simpler, but somewhat inaccurate formulation. In all cases, however, I wish it to be understood that the simpler formulation is merely a stand-in for the more cumbersome one, employed for purposes of explanatory simplicity.

Given this emendation, our focus needs to be on justification and defeat, ordinarily referred to respectively as the third and fourth conditions for knowledge. Confirmation that justification obtains relies on the special kind of internalism I am assuming here. If one is justified in believing $p$, then if the internalism in question is true, one can ascertain by simple reflection alone that one is so justified. Therefore, if one employed simple reflection to reach the conclusion that one is so justified, one's meta-belief would itself be justified. One may object here that this version of internalism is false, but I will not defend it here. It is worth noting, however, that any refutation of coherentism ought to undermine the standard versions of the view, and if the problem of justified inconsistent beliefs only undermines versions of internalism that are not internalistic in this way, that problem will not have the scope that its defenders have taken it to have. The usual versions

\footnotetext{
${ }^{13}$ This formulation also renders irrelevant any concerns about the appeal to closure in arguing that evidence for $p$ is evidence that $p$ is true.
} 
of coherentism endorse some version of this kind of internalism, standardly termed "access internalism", so it is fair to rely on it here to disarm the problem of justified inconsistent beliefs.

I will, however, throw one small bone to those who despise access internalism. I will qualify the requirement in a way that makes many, if not all, of the objections to the view otiose. In that way, those who don't like access internalism as normally described may still see in what follows the skeleton of a view that can survive their discomfort with access internalism.

Suppose then that a person is justified in believing a claim, reflects on whether the belief is justified, and concludes that it is. In such a case, the natural, and normally the best, explanation of what occurred is that the use of simple reflection operated in such a way so as to make the metabelief be properly based; the reflection in question did not create additional evidence on which to base the belief. If additional evidence were required to be produced in the process of reflecting on the epistemic status of belief, then the kind of internalism in question would be false, since something beyond reflection would be required to detect the epistemic status of one's belief. Instead, what would be needed is reflection that managed to be successful in producing the additional evidence needed to conclude properly that one's belief is justified. No, the access internalist holds that all that is needed to ascertain the justificatory status of a belief is reflection alone, not some sort of reflection that succeeds in producing additional evidence regarding the epistemic status of the belief in question. The picture is, rather, one in which, when a belief is justified for you, your total evidence prior to reflection already contains the information needed to conclude properly that the original belief was justified, and all that is needed to discover this information is simple reflection. Hence, a justification for believing $p$ obtains only if one's total evidence confirms that one is justified in believing $p$.

There are two complications to note here, both concerning the possibility that one has already reflected and come to the conclusion that one is not justified, thereby threatening the idea that simple reflection is sufficient to reveal the epistemic status of a justified belief. This general worry has two subcases. In the stronger case, one's reflection is assumed to have been adequate enough that one's meta-conclusion is itself justified. In such a case, the tempting description to give is that one has a justified false belief that one's belief is not justified. In the weaker case, the reflection has been careless and sloppy enough that no justification attaches to its meta-conclusion, in which case, the tempting description is that one believes falsely but without 
justification that a certain first-order belief is not justified.

In both cases, I maintain, the kind of reflection in question undermines the justification present prior to reflection for the first-order belief in question. Justification requires a body of information with two features. The first is sufficient evidence to confirm the truth of a given claim, but the second is that there is no further information that undermines the confirming power of the evidence in question. In both of the cases envisioned, reflection has generated a belief that, by itself, undermines the confirming power of whatever evidence one had prior to reflection; it has generated an underminer for the justification that was present prior to reflection. If you think that your total evidence is insufficient to show that the claim in question is true, if you think that your belief is unjustified, a sufficiently discriminating account of underminers should count you as having an underminer for whatever positive evidence you have for the first-order belief in question. ${ }^{14}$ In short, believing that grounds for doubt are present is itself a ground for doubt, and hence in these apparently problematic cases, new information is introduced by reflection that changes one's total body of evidence.

It is especially worth noting here that this point about believed defeaters constituting actual defeaters should be especially attractive to holistic versions of coherentism, which is to my mind the only plausible form of the view anyway. Holistic theories take into account the entirety of the belief system in determining what is justified, perhaps purging the belief system of elements not held in the interests of getting to the truth and avoiding error, as in the case of Keith Lehrer's version of the view. ${ }^{15}$ Whether one uses the entire belief system or a suitably purged subset of it, everything in the remaining system has a role to play in the story of justification, making the position above a quite natural one for holistic coherentists to adopt. As a result, the position above has both strong intuitive support and special support in the context of the appraisal of the prospects of coherentism. As already noted, the present difficulty attempts to undermine all versions of coherentism, so it cannot succeed simply by attacking only versions of the view lacking features that would be natural for defenders of the view to adopt.

Given this result, a suitably refined coherentism can refuse to embrace access internalism while still endorsing the idea that anytime a person jus-

\footnotetext{
${ }^{14}$ Michael Bergmann endorses such a claim in the most explicit manner among contemporary epistemologists, but he also argues that such a claim is implicit in the work of many leading epistemologists. See (Bergmann 1997, 2005).

${ }^{15}$ Lehrer 1974.
} 
tifiably believes $p$ in a way that puts one in a position to know, there is justification for believing that one is justified in believing $p$. This suitably refined coherentism begins by noting that it is a mistake to characterize the above examples in terms of the possibility of justified false beliefs about the justificatory status of one's first-order beliefs. Instead, the refined coherentist distinguishes cases where reflection is mistaken, thereby creating an underminer of justification, from cases where reflection is not mistaken. In doing so, the coherentist endorses only the following iteration principle about justification:

$$
J p \vdash J J p,
$$

where the operator ' $J$ ' is the operator of propositional justification. The coherentist can then go on to point out that access internalism is what you get when you try to operationalize this principle in terms of the process of reflection. As with other attempts at operationalization, problems arise for the theory that could be avoided by refusing to operationalize. So a suitably refined coherentism can be presented that refuses to operationalize and only endorses the iteration principle concerning justification. Thus, even if access internalism is ultimately rejected, coherentism can remain unscathed by the possibility that one reflects and comes to the conclusion at $t^{\prime}$ that one wasn't justified at an earlier time $t$ when in fact one was so justified. Refined coherentism - that refuses to operationalize the iteration principle in terms of what would happen when one reflects - can avoid such cases and still defend the conclusion that if one justifiably believes $p$, then one has justification for concluding that one has met the third condition for knowledge.

The astute reader will have noticed that the results so far have not employed any special feature of epistemic justification as opposed to ordinary justification. Instead, the results obtained by the special kind of internalism in question apply both to ordinary justification and epistemic justification, so long as ordinary justification is conceived to be internalistic in the same fashion assumed here for epistemic justification. In order to make good on the promise of distinguishing the two, there must be a crucial difference between them regarding the remaining condition for knowledge-the Gettier condition. It is what we should say about this condition, I believe, that distinguishes epistemic justification from ordinary justification. The key to understanding the distinction between the two kinds of justification is that one can be justified in the ordinary sense and also be justified in believing that further learning could upset one's epistemic applecart. That is just what 
happens in the lottery case. One is justified in believing that one's ticket will lose, but one also knows that further learning could involve reading in the paper that one's ticket won the lottery. Not likely, but it could happen.

This feature shows that ordinary justification is not the right kind for knowledge. Knowing involves a justified attitude of closure to further inquiry, confirmed by the fact that it makes little sense to say, "I know that it is raining outside, but I think I should go check to make sure," or to say, "I know today is Thursday, but further inquiry regarding today's date is probably appropriate." Just imagine a news conference in which the athletic director says, "We, together with the NCAA, have investigated all relevant charges of impropriety in the operation of our basketball program, and as a result, we now know that all of the charges are false and that our program is completely clean. But the investigation will continue..." Such a remark would be utterly bizarre, and the reason it would be bizarre is because knowledge involves a legitimate closure of investigation. In particular, it involves an inquiry that is of sufficient quality that it licenses the conclusion that any further learning could undermine one's present opinion only by presenting one with misleading information.

Some may want to say something stronger than that the above examples involve bizarre statements; they may want to insist that statements of the form, "it is known that $p$, but further investigation is appropriate" are contradictory. This account explains the oddity of such statements in semantic terms, whereas the last paragraph commits only the lesser claim that the oddity involves some pragmatic impropriety. For present purposes, it doesn't matter which account is correct, so I won't here argue for the weaker claim even though I believe it to be the correct account. What matters for present purposes is that, whatever the correct account of the impropriety of such statements, the impropriety is traceable to some feature concerning the quality of the inquiry that has been conducted (or the quality of one's knowledge-producing experience).

The way I am putting this point should not be confused with a stronger way of endorsing the present claim about the relationship between knowledge and further learning. One may be tempted here to say that inquiry adequate for knowledge licenses one to conclude that further learning could only confirm one's present opinion, but that it is too strong. It is too strong because of the possibility of misleading pockets of information. A simple statistical case will suffice as an example. Suppose statistical knowledge is possible, and that one's investigation has given one knowledge that most 
tosses of a given die are not sixes. It is consistent with such knowledge that were one to investigate further, that any finite string of sixes could result on future tosses of the die. Were further inquiry to occur and such an improbable sequence of events happen, one's opinion would have to change in order to be rational. What is licensed by one's present body of evidence on the assumption that this body of evidence is strong enough to put one in a position to know, however, is not the conclusion that no further learning could rationally undermine present opinion, but rather the weaker claim that any further learning that would rationally undermine present opinion would involve misleading information.

We need only tie this feature of epistemic justification to tie the notion of misleading information to the defeasibility theory to complete our response to the problem of justified inconsistent beliefs. It is well-known that knowledge is different from undefeated justified true belief, since some defeaters are misleading. I will not here present an account of the difference between misleading and non-misleading defeaters, since we don't need one for present purposes. All we need to do is to note the following. If one's total evidence confirms that further investigation could undermine present opinion only by uncovering misleading information, then one's total evidence confirms that further learning could at worst reveal only misleading defeaters. Hence, if one is epistemically justified in believing $p$, one is justified in concluding that one's justification is ungettiered, i.e., that one's justification is defeated at most by misleading defeaters.

We therefore have the results advertised. If one justifiably believes $p$ epistemically, one has justification for believing that all the non-psychological conditions for knowledge are met, i.e, that one has justification for concluding that (i) the content of the belief is true, (ii) one's total body of evidence confirms that content, and (iii) the justification in question is of sufficient quality that further investigation would undermine what is presently confirmed only be revealing misleading information. On the assumption that knowledge is justified true belief defeated by, at most, misleading defeaters, we get the desired conclusion that epistemically justified belief yields justification for thinking one has met the non-psychological conditions for knowledge.

It is precisely this condition that is missing in the ordinary notion of justification. Justification, in the ordinary sense, need not involve justification for thinking that one knows or that one has met the non-psychological conditions for knowing - that is precisely the lesson of the lottery and preface paradoxes. In such cases, the quality of one's evidence does not license a 
refusal to check the paper to see who won the lottery (though one's busy schedule might justify such a refusal) or a refusal to re-think some of the claims in one's wonderful book (though the attraction of further projects or the pressing nature of other responsibilities might). In this way, ordinary justification is weaker than epistemic justification, and it is this difference that the present argument exploits to avoid the problem for coherentism raised by the possibility of justified inconsistent beliefs.

One might think that this conclusion can be avoided. Instead of claiming that the closure feature of knowledge emphasized here is a product of the quality of one's justification, one might claim that this feature is a product of the combination of the justification condition plus satisfaction of the Gettier condition that is responsible for the closure feature we are trying to explain. If so, then the kind of justification necessary for knowledge would not yield justification for believing that the Gettier condition is satisfied. Instead, only a combination of justification plus satisfaction of the Gettier condition would yield such justification.

This viewpoint should be rejected, however. The closure feature we are trying to explain is an aspect of knowing that is licensed by the quality of one's investigation of or acquaintance with the issue at hand. As such, the licensing in question must be on the basis of the quality of one's evidence and not on some factor independent of that evidence, as any Gettier condition will be. When one's inquiry is sufficiently careful and detailed so that it is capable of yielding knowledge, it is the character of the inquiry itself and the quality of evidence it yields that justifies the conclusion that further inquiry would undermine present opinion only by revealing misleading information. Thus, the closure feature we are trying to explain must be explained in terms of aspects of the theory of inquiry that are involved in the justification condition for knowledge.

In a way, this point should be patently obvious. When your investigation is sufficient by your own lights, you have the closure experience that is distinctive of what is required for knowledge. Moreover, the closure experience is legitimated by the quality of your inquiry. So any plausible explanation of it must advert to the same features of that inquiry that make for justification, since that is how one acquires whatever evidence puts one in the position to justifiably believe that the claim in question is true.

With this conclusion, the version of the problem of justified inconsistent beliefs presently under discussion disappears. In the lottery case, one is justified in believing both that one's ticket will lose and that one does not 
know that one's ticket will lose; ${ }^{16}$ hence, the kind of justification in question is not epistemic justification. In the case of the preface paradox, one would not, or should not, claim to know that errors remain in one's work, even if one might voice psychological certainty of it. The same is true of our present system of beliefs: we have very good evidence that we have false beliefs, but it would be a mistake to say that we know this to be true (as opposed to saying "it very well might be true, and almost certainly is true"). In each of these cases, we have a justification for a set of claims that are inconsistent, but our total evidence does not also confirm that we know these claims to be true. Hence, in each case, the kind of justification in question is not the kind necessary for knowledge.

\section{Conclusion}

In concluding this partial defense of coherentism, it is important to acknowledge the limits of this defense. Apart from the question of whether all the details of my argument have been convincing, there is the more basic issue of the assumptions on which my argument relies. My argument assumes a version of internalism, a version of evidentialism, and a generic defeasibility approach to the Gettier problem. In light of these assumptions, one might think that my solution to the problem of justified inconsistent beliefs is rather limited.

I think not, however. These assumptions are far from unusual commitments of coherentism. In fact, it is very hard to find a version of coherentism not committed to all three assumptions. As a result, it is fair to say that the argument presented here can be embraced by nearly all coherentists, and those wishing to insist that the problem of justified inconsistent beliefs undermines coherentism will now have to change their tune. They'll have to argue against this fecund combination of internalism, evidentialism, and defeasibility theory that allows a distinction between ordinary and epistemic justification. I make no pretense here of having a good reason for accepting these assumptions, but even so, the results are useful, if only for showing what positions defenders of the problem of justified inconsistent beliefs must

\footnotetext{
${ }^{16}$ Though there may be senses of 'know' or contexts of utterance on which it is true to utter 'I know my ticket will lose'. I will pass over the complications introduced by these possibilities, since the backfilling needed to accommodate such points is likely fairly obvious to the reader.
} 
undermine if they wish to sustain the view that this problem undermines coherentism.

There is another limitation to this partial defense, however, that leaves quite a bit of work on the desk of the coherentist. To see the issue, consider the preface paradox again. Surely the coherentist does not want to hold that none of the beliefs expressed in the book count as knowledge. Yet, the solution to the problem of justified inconsistent beliefs presented leaves it an open question whether and how such knowledge is possible. The present discussion gives a schema for a coherentist answer: knowledge can be present for those claims that are epistemically justified, but not for those claims that are only justified in the ordinary sense of the term. Even so, the question of which aspects of the coherence relation will yield such a distinction is left unaddressed. In one way, that fact should not surprise, since as noted in the first paragraph, the precise nature of the coherence relation is the most significant promissory note for the coherentist to redeem. In another way, however, the present defense of coherentism creates an additional burden, that of explaining the distinction in question in coherence-theoretic terms. Since we don't even know how to explain ordinary justification in coherence-theoretic terms, this additional burden is not minor at all. In the end, coherentists might not be able to discharge this responsibility, and if they can't, coherentism must be abandoned.

One should not overestimate this pessimism, however, for this problem for coherentism is nothing more that a particular version of a very general problem. Any theory of justification will have to distinguish when the factors that make for justification are strong enough to put one in a position to know. If you are a reliabilist, this means you'll have to say how reliable a mechanism must be in order for a person to have knowledge; if you're a foundationalist, you'll have to say how strong the support offered by the foundations has to be in order for a person to be in a position to know. At the very least, then, the coherentist has a lot of company here. Moreover, as I pointed out in introducing the issue for this paper, we can make intellectual progress on a problem by changing the focus regarding what needs to be done in an adequate philosophical account. That is what I claim here: no longer need a coherentist gerrymander the theory in order to escape the problem of justified inconsistent beliefs. Instead, coherentists need only to present a clear account of the coherence relation, together with an explanation of what degree of coherence is sufficient for putting a person in a position to know. Since these issues are not new ones for coherentists, the present solution 
to the problem of justified inconsistent beliefs marks progress on behalf of coherentism. ${ }^{17}$

\footnotetext{
${ }^{17}$ Special thanks to Jack Lyons, Peter Markie, and Matt McGrath for useful comments on previous drafts.
} 


\section{References}

Bergmann, M. (1997). "Internalism, Externalism, and the No-Defeater Condition". Synthese, 110:405-407.

Bergmann, M. (2005). "Defeaters and Higher-Level Requirements". The Philosophical Quarterly, 55.220:419-436.

BonJour, L. (1985). The Structure of Empirical Knowledge. Cambridge, Mass.: Harvard University Press.

BonJour, L. (1999). "The Dialectic of Foundationalism and Coherentism". In Greco, J. and Sosa, E., editors, The Blackwell Guide to Epistemology, pages 117-144. Malden, MA: Blackwell.

Bovens, L. and Hartmann, S. (2003a). Bayesian Coherentism. Oxford: Oxford University Press.

Bovens, L. and Hartmann, S. (2003b). "Solving the Riddle of Coherence". Mind, 112:601-634.

Chalmers, D. (2004). "Epistemic Two-Dimensional Semantics". Philosophical Studies, 118:153-226.

Dougherty, T. and Rysiew, P. (2009). "Fallibilism, Epistemic Possibility, and Concessive Knowledge Attributions". Philosophy and Phenomenological Research, 78.1:123-132.

Foley, R. (1979). "Justified Inconsistent Beliefs". American Philosophical Quarterly, 16.4:247-257.

Garcia-Carpintero, M. and Macià, J., editors (2005). Two-Dimensional Semantics: Foundations and Applications. Oxford: Oxford University Press.

Kvanvig, J. L. (1995a). "Coherentism: Misconstrual and Misapprehension". Southwest Philosophy Review, 11:159-169.

Kvanvig, J. L. (1995b). "Coherentists' Distractions". Philosophical Topics, $23: 257-275$.

Kvanvig, J. L. (2003). "Propositionalism and the Perspectival Character of Justification". American Philosophical Quarterly, 40.1:3-18. 
Kvanvig, J. L. and Riggs, W. D. (1992). "Can a Coherence Theory Appeal to Appearance States?". Philosophical Studies, 67:197-217.

Lehrer, K. (1974). Knowledge. New York: Oxford University Press.

Lewis, D. (1996). "Elusive Knowledge". Australasian Journal of Philosophy, 74.4:549-567.

Lycan, W. G. (1996). "Plantinga and Coherentisms". In Kvanvig, J. L., editor, Warrant in Contemporary Epistemology, pages 1-25. Savage, Maryland: Rowman and Littlefield.

Pollock, J. L. (1986). "The Paradox of the Preface". Philosophy of Science, $53: 246-258$.

Pollock, J. L. (2001). "Defeasible Reasoning with Variable Degrees of Justification". Artificial Intelligence, 133:233-282.

Stanley, J. (2005). Knowledge and Practical Interests. Oxford: Oxford University Press. 